\title{
Investigating Opportunities to Learn Mathematical and Graphing Skills in Imperfect Market Structures
}

\author{
Wellington Manzi, Moeketsi Mosia*, Boitumelo Moreeng \\ Faculty of Education, University of the Free State, 301, Bloemfontein, South Africa
}

Received January 3, 2021; Revised April 29, 2021; Accepted May 16, 2021

\section{Cite This Paper in the following Citation Styles}

(a): [1] Wellington Manzi, Moeketsi Mosia, Boitumelo Moreeng, "Investigating Opportunities to Learn Mathematical and Graphing Skills in Imperfect Market Structures," Universal Journal of Educational Research, Vol. 9, No. 6, pp. 1113-1123, 2021. DOI: 10.13189/ujer.2021.090601.

(b): Wellington Manzi, Moeketsi Mosia, Boitumelo Moreeng (2021). Investigating Opportunities to Learn Mathematical and Graphing Skills in Imperfect Market Structures. Universal Journal of Educational Research, 9(6), 1113-1123. DOI: 10.13189/ujer.2021.090601.

Copyright $\bigcirc 2021$ by authors, all rights reserved. Authors agree that this article remains permanently open access under the terms of the Creative Commons Attribution License 4.0 International License

\begin{abstract}
The concept of imperfect market structures enables learners to develop mathematical and graphing skills that are needed for them to be critical thinkers and to be able to solve problems faced in their daily lives. It also provides opportunities for learners to acquire economic knowledge, which enables them to make informed economic decisions on economic events and issues they will experience as they enter the world of business and work. In spite of the importance of imperfect market structures in cultivating these skills and knowledge, learner academic achievement in economics, particularly where mathematical and graphing skills are concerned, has been regrettably poor in most countries around the globe. Hence, this qualitative study investigated the opportunities to learn mathematical and graphical skills in imperfect market structures in three selected Grade 12 economics classes. The study intended to investigate what it is that teachers do in the name of teaching and learning of mathematical and graphing skills and the reasoning behind their actions. Opportunities to Learn (OTL) is the conceptual framework which was used to determine what teachers do in the classroom that enables learners to make sense of imperfect market structures. Using the case study approach, the study was operationalised by three conveniently selected economics teachers in the Galeshewe township in South Africa. The researcher conducted semi-structured interviews with each of the three teachers before they conducted their classes which the researcher observed. The findings of the researcher show that little or no opportunities to learn are provided in an imperfect market
\end{abstract}

structure class.

Keywords Imperfect Market Structures, Economic Events, Opportunities to Learn, Graphing Skills

\section{Introduction}

The increasing use of graphs and tables on television, the internet, newspapers, and other platforms has necessitated the need for mathematical and graphing skills so that learners can make sense of information conveyed on such platforms. Imperfect market structure is an economics concept that creates an opportunity for learners develop such skills. Imperfect market structures are market structures where there is some degree of unfair competition and each of them is distinguished according to its characteristics [1]. The content of these market structures, as postulated by [2] exposes learners to the interpretation of numbers, graphs, tables and equations.

The graphing and mathematical principles used in economics are borrowed from the discipline of mathematics. In fact, scholars such as [2] postulate that learners need a code breaker found in mathematical competence for them to be able to encode and decode graphs. Also, it is important to note that graphs in economics are built on the mastery of mathematical concepts as postulated by $[3,4]$ when they explicitly state the heavy reliance of economics on mathematics and 
statistics. The interconnectedness of economics and mathematics is further shown by a positive correlation between performance in mathematics and economics classes in a study by [5] on the relationship between mathematics and economics achievement. Based on the foregoing, it can be argued that mathematical and graphing skills are critical in the learning of economic concepts like imperfect market structures. Without mathematical competence, it becomes complex for learners to master economic graphs in imperfect market structures as they will be faced with two complex tasks: that of mathematics and linking mathematics to graphically model human behaviour on decisions they make.

Notwithstanding the above, literature, such as [6] shows that learners of all ages face challenges in mathematical and graphing skills. A lack of basic mathematical operations, interpretation, modelling, conversion skills, an inability to work with data, and limited understanding of the usefulness of mathematical and graphing principles in economics are cited as possible reasons for the challenges $[4,7,8]$. In addition, [12] have stated that learners find it difficult to define variables and to connect graphs with variables.

The above challenges only focus on what learners cannot do and despite the increase in documented evidence of research on learners' challenges of mathematics skills in economics, including the studies referred to above, little is known about the opportunities to learn created for learners to develop the requisite graphing and mathematical skills. Thus, an article of this nature may help to answer what and how opportunities to learn mathematical and graphing skills in imperfect market structures are created in a grade 12 economics class by answering the following questions:

1. What opportunities to learn mathematical and graphing skills in imperfect market structures are created by economics teachers?

2. How are the opportunities to learn mathematical and graphing skills in imperfect market structures created by economics teachers?

3. What are the challenges faced in creating opportunities to learn mathematical and graphing skills in imperfect market structures by teachers?

\section{Literature Review and Conceptual Framework}

The review of literature in this section seeks to provide answers on what is already known about OTL in order to present a conceptual framework for examining the grade 12 economics learners' perceptions on opportunities to learn imperfect market structures. This section focuses on the challenges which are faced by learners in trying to make sense of mathematical and graphing skills embedded in imperfect market structures.

\subsection{Inability to Work with Data, Lack of Interpretation, Modelling, and Conversion Skills}

According to [10] the inability to work with data and lack of interpretation, modelling, and conversion skills are stumbling blocks in the learning of mathematical and graphing skills. He argues that learners are unable to make inferences from given data. It is [10] contended that learners have difficulties in summarising, condensing, and displaying quantitative data. A study by [11] revealed that learners in a 10th grade class had difficulties understanding the relationship of dependent and independent variables represented by the $\mathrm{y}$ - and $\mathrm{x}$ axis. It can be reasonably argued that this could be the possible reason why learners are not able to observe trends in marginal costs, marginal revenue, and average revenue of imperfect market competitors in the short and long run.

Given the above challenge, literature suggests that learners should also be bound to manifest deficiencies in interpretation, modelling, and conversion skills $[4,7,8]$. As [4] puts it, interpretation refers to the ability to express a graph in words, modelling is the ability to express an observed state through graphs, and conversion is concerned with drawing a different graph to show the same state given in a graph. It is reasonable to argue that, if learners cannot make meaning of the data they are given, they will find it difficult to model the given data into graphs. In fact,[9] are of the contention that learners do not have mental tools to engage in a high construction and interpretation of graphs. This poses a difficulty in comprehending the concepts in imperfect markets as learners are not able to read and display visual data.

\subsection{Problems Defining Variables and Connecting Graphs with Variables}

Another challenge which affects learners' graphical ability is that learners often struggle to see the relationship between mathematical graphs and the data they represent $[4,10,11,12,13]$. These scholars believe that there is a misconception whereby learners view graphs as pictures and not as a relationship between variables. This challenge carries over into other areas of study such as imperfect market structures which require an understanding of the correlation between information and representation. Instead of looking at the variables such as marginal cost, average revenue, demand curve, average cost, marginal revenue, and quantity, [10] states that learners view these graphs as representing literal pictures of situations rather than quantitative information.

It is the contention of [14] that before learners engage in the drawing of a graph, they must understand the data and decide how they want to transform it. This calls for the ability to define the variables and to be able to see how these variables are related. Once the above have been achieved, [14] posit that "a graph is constructed with appropriate elements" of graph mechanics for clear 
communication. To be able to do this, there is a need for a great deal of mathematical competence.

\subsection{Limited Understanding of the Usefulness of Mathematical Principles in Economics}

Lapp \& Cyrus [12] postulate that learners do not see the connection between economics and mathematics and therefore fail to apply the knowledge of mathematics and graphing skills acquired in mathematics. Learners fail to realise that mathematical concepts enable them to describe concepts in terms of equations, for instance. These mathematical concepts make it possible to predict the behaviour of economic actors in imperfect market structures. In addition, [14] argue that mathematical principles and graphs make it easy to summarise large sets of data, however, learners view these as stumbling blocks in their learning of economic concepts. It can be argued that, given the global trend of low learner competency in mathematics, learners will perform similar in imperfect market structures given their mathematical backlogs.

It is unclear how learners are being taught the mathematical and graphing skills in imperfect market structures. For this reason, the researcher settled for OTL as the conceptual framework couching this study because it gave the researcher the lens to investigate all that teachers are doing to promote or hamper the teaching and learning of imperfect market structures.

The concept of OTL was initially introduced to ensure the validity and comparability of cross-national comparison in the First International Mathematics Survey (FIMS) in the early 1960s $[15,16,17,18]$. It was used in studies of mathematics achievement conducted by the International Association for the Evaluation of Educational Achievement (IEA). OTL measured whether or not students had the opportunity to study the particular topic or learn how to solve a particular type of problem [19]. It is the contention of [15] that ideas and concepts like OTL can greatly contribute to defining policy problems and in framing solutions.

Scholars view OTL as information about resources, school conditions, curriculum, and instruction to which students have access to $[20,21,22,23]$ goes further to argue that OTL measures the conditions within the school or classroom that promote or hamper learning. The above definitions show that the main thrust behind OTL is that learning outcomes may be explained by the curriculum content, instructional strategies, and instructional resources. Thus, this paper will use these three constructs to investigate the opportunities learners have to learn mathematical and graphing skills in imperfect market structures.

\subsection{Quality of Instructional Delivery}

Walkowiak, Pinter, and Berry [24] view quality of instructional delivery to include the teacher's pedagogical strategies and understanding of the subject matter. Unfortunately, a study of 46 teachers in a high school conducted by [25] on mathematical understanding revealed that most teachers had misconceptions and challenges in applying numerical knowledge for solving mathematical problems. On the contrary, [26] argues that effective and fruitful learning in economics is dependent upon the quality of teaching which demands academically competent individuals. In addition, [27] posits that only effective teachers can facilitate the acquisition of mathematical and graphing skills.

\subsection{Instructional Resources}

Gilles and Quijada [28] conceptualise instructional resources to incorporate a broad category of education-related resources such as textbooks, instructional guides, workbooks, practise exercises, activities, and tests. Although [29] concur with the above conceptualisation, they go further to include professional development and attitudes as part of instructional resources. From the foregoing, the researcher finds it reasonable to conceptualise instructional resources as both human and physical aspects which affect teaching and learning.

Handayani [27] contends that, for the economics learning process to be done properly, teachers must be innovative. Learning resources should be adequately used as they affect the effectiveness of a teacher's lesson [30].Well-planned and imaginative use of visual aids in the teaching of imperfect market structures prevent apathy, supplement the inadequacy of books, and arouse learners' interest and develop the requisite skills of problem solving and critical thinking as envisaged in the economics curriculum.

\subsection{Curriculum Content Coverage}

Curriculum content refers to the extent to which learners have been exposed to specific subjects or topics that are essential to attaining particular standards and /or that are directly assessed [29]. This variable seeks to identify whether the learners were exposed to the content, whether the content was covered adequately, and whether important concepts in the curriculum were emphasised. This can be related to [21] view of OTL which he regards as matching taught content with tested content. Scheerens [21] argues that it is unfair for learners to be held responsible for meeting high academic standards unless they have been assured of the opportunities to learn. Thus, curriculum coverage is of interest to the researcher as it will provide valuable data in terms of OTL mathematical and graphical skills in imperfect market structures.

\section{Research Methodology}

The study made use of a case study design which is a 
qualitative research approach. Qualitative data collection techniques were employed to gather "rich description and / or meaning of lived experience". [31] This suited this study as the researcher sought to investigate how opportunities to learn mathematical and graphing skills in imperfect market structures are created. The choice of a qualitative approach was based on the premise that the approach acknowledges that people give meaning to phenomena and that there are multiple realities of the phenomena which differ across space and time. Research participants were interviewed and observed in their natural settings, namely the schools and classrooms [32]. The semi structured interviews allowed the researcher to have follow-up questions to get clarity as the interviews progressed. This is in line with ensuring credibility and trustworthiness of the findings as this semi structured interviews allowed member checking.

The use of triangulation ensured that the issue was not explored using one lens but rather a variety of lenses. This allowed for multiple facets of the phenomenon to be revealed and understood [33]. This approach also assisted in removing doubt about the trustworthiness and credibility of the research findings. A case study is "an empirical inquiry that investigates a contemporary phenomenon in depth and within its real-life" [34].

The case study approach was adopted because it allowed the researcher to "systematically inquire into an event or set of related events which aims to describe and explain the phenomenon of interest", viz. opportunities to learn mathematical and graphing skills in imperfect market structures [35].

\subsection{Description of Participants and Reasons for Their Inclusion}

Three teachers participated in this research, two male teachers and one female teacher who are teaching grade 10-12 from two neighboring suburban secondary schools in the Northern Cape province of South Africa. One of the male teachers has Bachelor of Education Degree (B.Ed.), the other has a Diploma in Education and the female teacher has an Advanced Certificate in Education (ACE). The participants selected had 18 and 24 years of teaching experience whilst the third participant was a novice teacher. The researcher was of the view that selection of teachers with varying levels of experience would minimize questions to do with experience as a factor affecting the findings. The two schools were purposefully selected because of their proximity to the researcher and they have been deemed to be underperforming schools for the past three years yet two of the teachers teaching in both these schools are experienced teachers. A school is deemed by the Department of Basic Education to be underperforming in a subject if the pass rate is below $50 \%$.

\subsection{Data Generation}

The sources of data for this study were structured interviews and classroom observations. One of the merits of one-on-one interviews is that they provide face-to-face interaction for the researcher and the respondent in order to promote access to their life experiences in their natural setting $[36,37]$. An observation protocol was used to guide the observations. During these observations, the researcher was able to hear, see, and experience real opportunities in learning mathematical and graphical skills in imperfect market structures [35]. As a guide to the observation, the researcher was interested in establishing the extent to which the teacher exposed learners to calculations and graphs (curriculum content coverage), how the calculations and graphs were taught (quality of instruction) and the nature of instructional resources.

\subsection{Data Analysis}

Data for this article was analysed qualitatively through the use of the inductive method. This method, according to [36], allows for the data collected to be categorized into themes, patterns, or categories and then interpreted. The data generated from interviews were audio recorded and themes were formed from the two sources of information according to the differences and similarities of the data obtained.

\subsection{Ethical Consideration}

The researcher obtained ethical clearance from the University of the Free State (UFSHSD2018/0378) to conduct this research. Permission was sought from the participants and parental consent was obtained for those participants who were under the age of 18. Participants' confidentiality was always upheld throughout the research process and the participants were made aware that they could withdraw from participating any time they deemed necessary. Note: In line with ethical requirements, the names of the teachers and schools were changed for anonymity.

\section{Findings}

The study sought to answer three questions on "What" and "How" opportunities to learn mathematical and graphing skills in imperfect market structures are created by economics teachers in a grade 12 class and the challenges learners faced in comprehending the concept. The findings suggest that economics teachers have not created enough opportunities to learn. Data are presented in the following section under three basic constructs of OTL: curriculum content, instructional strategies, and instructional resources. 


\subsection{Curriculum Content}

In imperfect market structures, the relationship between variables, data analysis, modelling and interpretation of graphs, and calculation of profits and costs must be given priority if learners are to acquire the relevant knowledge and skills [4]. It was therefore necessary for the researcher to investigate how teachers create the opportunities for learners to learn mathematical and graphing skills in imperfect market structures. It was interesting to see how different teachers had an almost similar approach in the teaching of mathematical and graphing skills. When asked in the interview what depth and emphasis is placed on the teaching and learning of the actual calculations of costs and revenues, most teachers admitted that they do not give much attention to this aspect. This was evident from the responses from Mr T.T. who had this to say:

Mmm not much depth, you know, the curriculum is packed and there is a lot of work to cover...

Ms V.V. seemed to support the sentiments echoed by $\mathrm{Mr}$ T.T. that there is a lot of work to cover although she also goes further and confesses that the other reason for not spending much time on calculations and graph construction was that she was not confident in the content. She confessed experiencing difficulties with this concept from her days in high school, college, as well as in her teaching career. This is what she had to say about time spend on calculations and graphing skills:

You see these calculations are not easy even for me. This section of the curriculum has been a challenge for me since my high school days and even at college. I just don't like calculations and graphs. Besides, there is a lot of work to be covered that I cannot spend time on things that are difficult for me and worse for the learners.

Mr GK" s response on the emphasis he placed on the concept imperfect market structures pointed to a far better emphasis on the concept than the two teachers as he said:

"Ooh yes I try to emphasis on calculations of costs and revenues but not necessarily in class, these kids are slow to grasp concepts which involve mathematical applications that we might not complete the syllabus, so, what I do is to give them a collection of questions to do at home, that way they practise on their own.

Although it is evident that learners are given opportunities to answer questions based on calculations of costs and revenues at home on their own, it cannot be assumed that the learners grasp these concepts without the teacher's guidance. It is a good practice to give learners homework [38], however, the teacher has to reinforce certain concepts in class especially given the challenges which learners generally face with mathematical concepts. The learner's limitations on calculations can only be solved with interactions with the teacher and their peers. As [39] posits, homework can be a passive learning instrument if it replaces deep meaningful interactions in the classroom.

On the question of in what depth the relationship between variables in table forms such as costs, profits, and revenues were taught to learners, Mr T.T. had this to say:

Ok like I said earlier, there is no time to focus on a lot of things. And these learners should do extra. They should not just wait for teachers to do everything for them.

It is clear from his responses that calculations are given less attention. The same sentiments were echoed by Ms V.V. who had this to say about the time spent and the depth of the teaching and learning of the actual of calculations of different costs and revenues:

I must quickly rush through the calculations because the grade 12 year is very short - just six months of contact time - and there is a lot of work to be done. One must make sure they cover the work otherwise you will be in trouble with the departmental officials who come to monitor if we have taught everything in the syllabus.

On how deep Mr Gk taught the relationship between variables he had this to say:

One cannot spend more time on concepts which are difficult to the learners and I have never seen a question based on the relationships of those costs and variables you are asking about.

True to their interview assertions, the researcher, through lesson observation, found that little time or no emphasis was given to the explanation of the relationship between variables in table forms such as costs, profits, and revenues. In Mr. T.T.'s lesson, the teacher never went through the different variables such as marginal costs, marginal revenue, average costs, and the trends of those costs and revenues. The teacher just went straight on to draw the graph of a monopoly. The other observation was that there were no numbers used to help learners to interpret the concept and see the relationship between variables. This is evident from the graph below which was drawn in class:

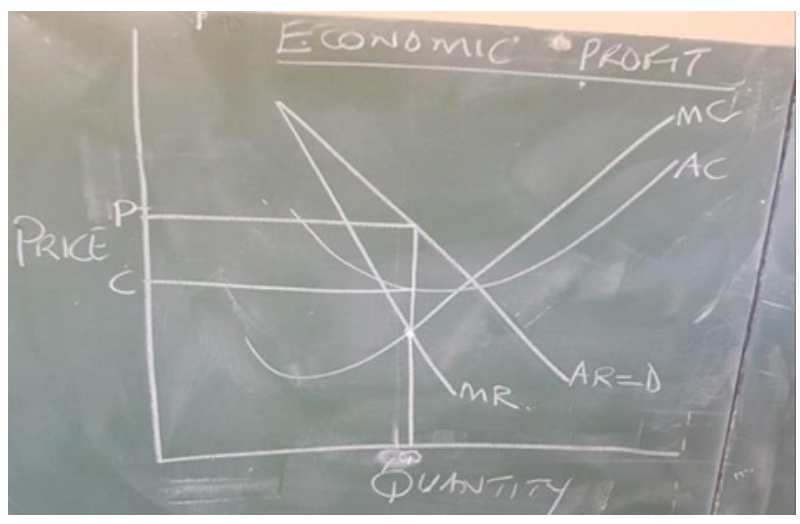

Figure 1. Monopoly graph drawn in class by Mr. T.T 
The above graph was drawn without providing the background information of the price, the cost, the marginal cost, and the average costs. Simply drawing a graph without reference to price and various costs does not allow learners to see the relationship between variables but rather to see the graph as a complete picture.

In Ms. V.V.'s lesson, although she wrote the different costs on the board, learners were not given an opportunity to interact with the costs and revenues so that they could see the relationships between and trends in these costs and revenues. The costs and revenues were used but the learners were not first shown how to draw each curve separately in order for them to see the behaviour and relationship between different costs and revenues. This probably explains why learners could not calculate the different costs and revenues as evidenced by their poor performance on the common task (project) set by the Northern Cape department of education (refer to figure 2). Most learners performed poorly because the task required learners to make calculations of marginal cost, marginal revenue, and average revenue which the learners were not exposed to in the classroom.

The project also required learners to draw marginal and average cost curves on a graph using the data which they had to calculate in figure 2 . The document learners' scripts showed that most learners could graphically depict the cost curves. The learners did not understand the behaviour of marginal cost as shown in figure 3 below.

The following table indicate the relationship between the different cost items:

1.1 The following table indicate the relationship between the different cost items:

\begin{tabular}{|c|c|c|c|c|c|c|}
\hline Output & $\begin{array}{l}\text { Fixed } \\
\text { costs }\end{array}$ & $\begin{array}{c}\text { Variable } \\
\text { costs }\end{array}$ & $\begin{array}{l}\text { Total } \\
\text { costs }\end{array}$ & $\begin{array}{c}\text { Increase } \\
\text { in } \mathrm{TC}\end{array}$ & $\begin{array}{c}\text { Average } \\
\text { costs }\end{array}$ & $\begin{array}{c}\text { Marginal } \\
\text { costs }\end{array}$ \\
\hline 1 & 10 & 40 & 50 & - & - & \\
\hline 2 & 10 & 45 & 55 & 5 & (1)........... & (5)............ \\
\hline 3 & 10 & 48,5 & 58,5 & 3,5 & (2)...30... & (6)............ \\
\hline 4 & 10 & 53 & 63 & 4,5 & (3)...42 7 & (7).......... \\
\hline 5 & 10 & 60 & 70 & 7 & (4)......... & (8)......... \\
\hline 6 & 10 & 74 & 84 & 14 & ? & $?$ \\
\hline 7 & 10 & 95 & 105 & 21 & & $?$ \\
\hline 8 & 10 & 124 & 134 & 29 & ? & $?$ \\
\hline
\end{tabular}

1.1 Complete the table by filling in the missing figures

(8)

Figure 2. Learners' errors on calculating average and marginal cost

1.2 Graphically depict the two costs curves (AC, MC)

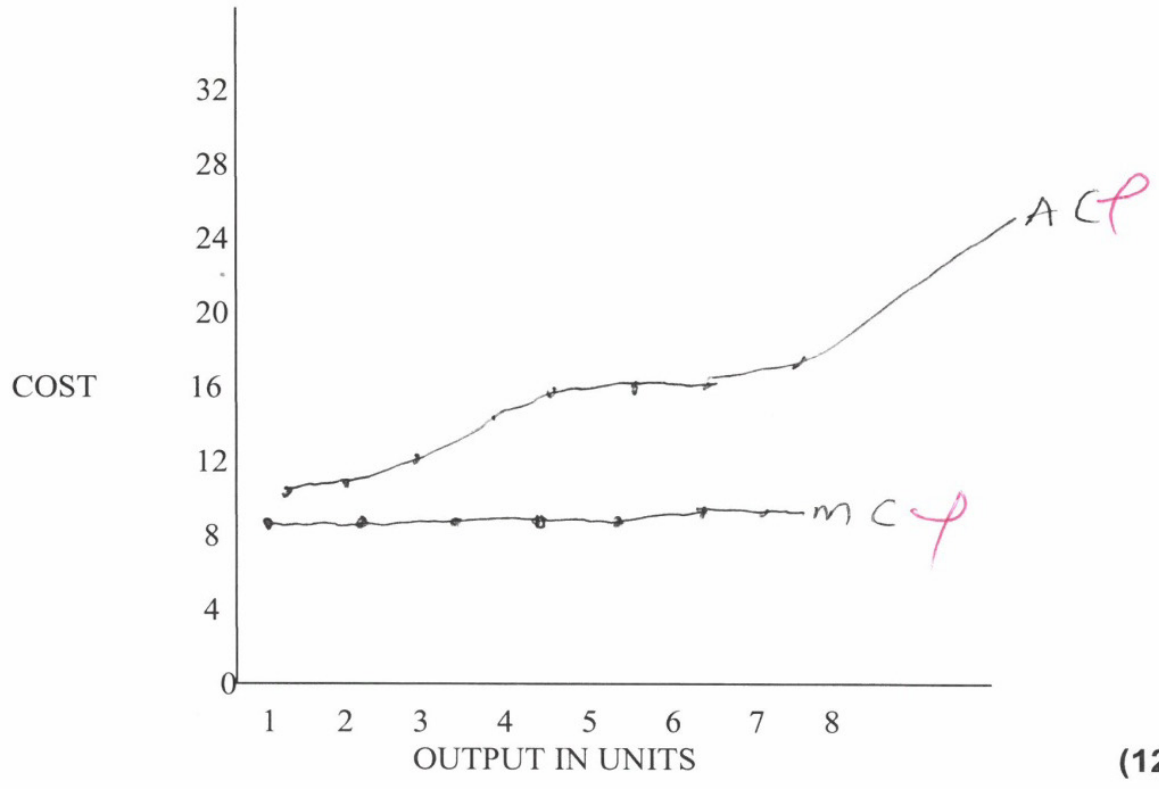

Figure 3. Learners' errors drawing cost curves 

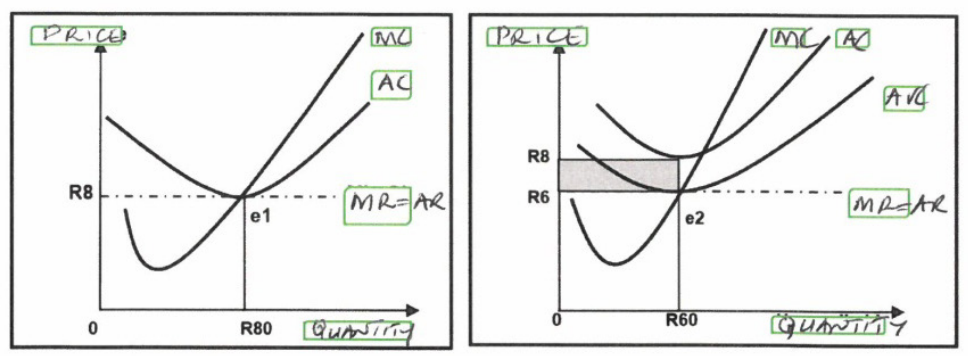

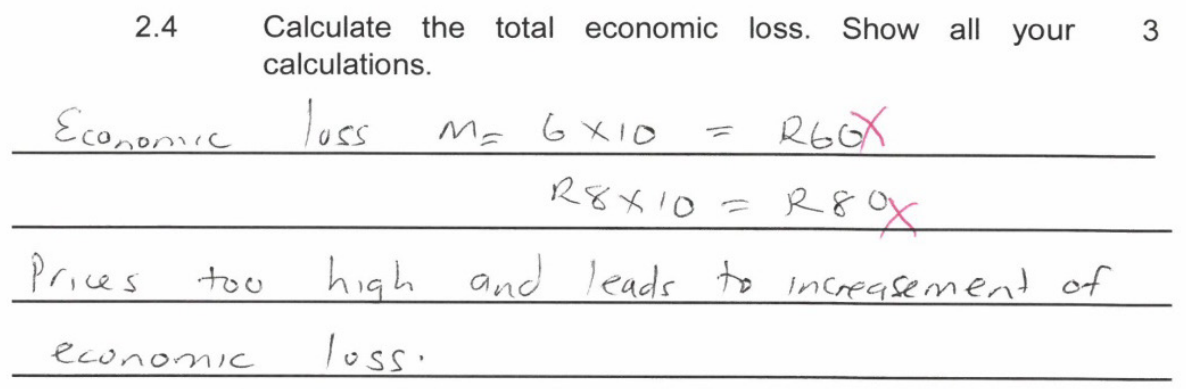

Figure 4. Learner's response on calculation of a loss

It is reasonable to attribute this challenge to their lack of understanding of the relationship between the costs and revenues. Morrison and MacDuffie [40] would have us understand that learners must be challenged with relevant tasks which include data analysis and interpretation if they are to be able to see these relationships. However, this was not the case and learners were not given the opportunity to learn graphical and mathematical skills.

The learner's scripts revealed that learners could not calculate profit or loss (see figure 4). The lack of meaningful class activities where learners practise these calculations could be a possible explanation. A review of literature reveals that learners can only be held accountable for their performance to the extent that they have been offered tools to master the content [15]. It can therefore be argued that the lack of opportunities to learn may be one of the contributors to poor performance by the learners.

\subsection{Quality of Instruction}

Today, as [41] argues, the role of a teacher has been transformed from a transmitter of knowledge to a co-learner and a facilitator of learning. Sadly, the data gathered from the selected schools, through interviews and observation seemed to prove otherwise. This was regardless of the fact that the researcher, through the interviews with teachers, had gathered that teachers seemed to have a general idea of the prescripts of the Curriculum and Assessment Policy Standards (CAPS) which dictates that learners be actively involved in the learning process. The quality of instruction seems to fall far below what is provided by literature as an enabler of meaningful learning. Such is the disjuncture between policy and practice that is often observed by researchers. The disjuncture between policy and the practice of teachers is evident from the interview conducted with Mr T.T. who had this to say on whether he varied his instructional strategies:

I will draw the graphs on the board and then explain them.

Upon further probing on whether he varied his teaching methods he had this to say"

No, no - not with this group. They are noisy. I can't give them that chance to discuss in pairs or groups and you will see it's a big class of forty-two learners.

The use of teacher-centred method (lecture) was also favoured by Mr G.K. For him, that was the most appropriate strategy to use in teaching calculations and graphs:

The only way I can make these learners understand the concept is when I explain it myself. The calculations I leave them to figure out themselves, we won't move yet there is limited time and a lot of work to be done.

In Ms V.V"s class she had this to say:

"These kids only listen and work when I stand in front of them with a serious face, thus I cant afford to give them group or pair work, it will be a waste of time"

It becomes clear that the teachers do not vary their teaching strategies and learners are not given an active role 
in the learning process. This approach is in sharp contrast to the dictates of literature $[42,43,44]$ which advocates for active learner involvement. Interestingly and true to his assertions in the interview, $\mathrm{Mr}$ T.T. made sure that learners played a minimal role in the lesson proceedings presumably for the fear of noise and disruptive behaviour that he had alluded to earlier in the interview. Similar trends were observed in Ms V.V.'s class where learners were not actively involved in the learning process. Graphs were drawn by the teacher and learners were asked to copy the graphs into their books quietly.

Similar trends were prevalent in Mr G.K.'s lessons where he drew the graph of an oligopoly without any explanations or exposure of marginal costs, marginal revenue, average revenue, and other related costs. The teacher then explained the graph to the learners. This approach to graphs is bemoaned by scholars such as [45] who allege that this approach is one of the causes of poor mathematical and graphing skills as it results in learners' failing to convey visual information and consequently see graphs as complicated visual representations. In his explanation of the complete graph, Mr G.K. would continuously ask learners "Do you understand?" to which some learners would shyly nod their heads, and some would just remain silent. These types of questions asked by Mr G.K. did not probe learners to think critically and solve problems. Interestingly, the document analysis of Ms V.V.'s learner portfolios revealed that the questions posed to learners as homework did not create opportunities for learners to acquire mathematical and graphing skills. Questions such as "How does a marginal curve look like?" have no value in assisting learners to acquire the requisite skills like critical thinking or problem solving. This is against the new paradigm of learning which contends that learners acquire understanding when they take an active role and seek solutions to given problems on their own.

\subsection{Instructional Resources}

Nilson [46] view instructional resources as "enabling input" which makes discovered facts firmly etched into the memory of the learners. Data from this research, however, suggests that instructional resources were not being used adequately in trying to etch graphing and mathematical skills firmly into the learners' memories. From the interview with Mr T.T., it was apparent that the only resources which he was going to make use of were the chalkboard and past question papers which were used for learners to answer questions based on the monopoly graph. The use of past question papers which examined learners on all the aspects of graphing and mathematical skills at once is inappropriate as the final skills and knowledge are tested. Yet literature suggests that there should be a build-up of activities towards drawing and interpretation of the graphs [14] Interestingly, a perusal of Ms V.V.'s teacher file showed a compilation of questions on imperfect market structures from past question papers from 2014-2017 which she termed as "question bank". Learners had to do these activities, but sadly most of them seemed to perform badly. This can be attributed to these learning resources not enabling learners to comprehend the requisite mathematical and graphing skills.

\section{Discussion}

The main research question for this article was "what opportunities to learn mathematical and graphing skills in imperfect market structures are created by economics teachers?" Based on the analysis of learners' responses, the researchers conclude that little opportunities to learn mathematical and graphing skills in imperfect market structures are being presented in an economics classroom. The work of [14] as earlier alluded to suggests that there should be a build-up of activities towards drawing and interpretation of the graphs. However, this was not the case from the data gathered. The teachers in the case studies went straight to depict the graphs as complete pictures without taking learners step by step as suggested by literature. This could probably be the reason why scholars such as [9] bemoan the lack of mental tools on the part of learners to engage in a high construction and interpretation of graphs as this skill is not practiced in class. The study findings also reveal that less emphasis is being placed on the calculations of different costs and revenues. This practice, in sharp contrast to literature such as [40], suggests that learners have to be given challenging tasks which allow them to analyse data and see relationships of variables. This finding might confirm what the teachers suggested when they were interviewed by the researchers that they were working under pressure and were in a hurry to complete the syllabus. There is also a possibility that maybe the lack of confidence in mathematics and graphing skills, as voiced by one of the teachers in the interviews conducted by the researcher could be the reason why the teachers rushed through the work and, in the process, omitted fundamental aspects of mathematical and graphing skills.

From the data generated, it was also evident that teachers dominantly relied on the traditional lecture method which diminishes learners' interest in imperfect market structures. This conclusion was arrived at based on the responses by Mr GK and TT who admitted to their over-use of the lecture method. This is in direct contrast to what literature suggests in advocating for a collaborative, interactive learning environment as opposed to a passive learning environment $[4748,44]$. The quality of some of the activities given to the learners did not add value in terms of assisting learners to gain the requisite mathematical and graphing skills. This finding further supports the earlier assertions by scholars like [44] who posited that teachers do not present their subject in meaningful ways probably 
because they lack pedagogical content knowledge. The most used resource was the chalkboard and past question papers and these two resources alone cannot ignite learners' interest.

\section{Conclusion and Recommendations}

The findings of this study suggest that economics teachers, who participated in this study, do not create adequate opportunities to learn mathematical and graphing skills in imperfect market structures. This is based on the premise that mathematical and graphing skills were not emphasised in the cases studied. The quality of instructional strategies had limitations as the lecture method was dominant in both schools. Learner centered approaches are significantly important since they increase learner's motivation and engagement level. It was also observed that teachers generally present learners with exercise that only require low cognitive demand, yet the concept requires learners to be critical thinkers and problem solvers. Teachers need to create opportunities for engagement through deeper classroom discussions around calculation of costs and revenues, drawing and interpretation of graphs if the objective of the concept that of problem solving and critically thinking is to be achieved.

This study was limited to three schools with almost similar socio-economic backgrounds. While results of this study may be extended to other teachers and learners in similar contexts, it is important to generalise with caution.

The article recommends a follow-up study with a larger sample from different schools with different socio-economic conditions to get a more representative picture of pedagogical strategies and knowledge for teaching mathematical and graphing skills in more diverse educational contexts.

Please note that this article was submitted as part of a Masters dissertation at the University of The Free State

\section{REFERENCES}

[1] Department of Basic Education (DBE). Report on the Annual National Assessments of 2014. Pretoria: Department of Basic Education, 2014.

[2] Arsaythamby V., P Juliminary, "Student's Perceptions on Difficulties of Symbols, Graphs and Problem Solving in Economics," Social and Behavioural Siences, 177: 240245,2014

http://creativecommons.org/licences/by-nc-nd/4.0/)

[3] Dawson L. Skills in Mathematics and Statistics in Economics and tackling transition, York: Higher Education Academy,2014

[4] Gultepe N. "Reflections on High School Students' Graphing Skills and Their Conceptual Understanding of
Drawing Chemistry Graphs," Educational Sciences: Theory \& Practice, 16, 53-81, 2016. DOI: 10.12738/estp.2016.1.2837

[5] Khoo Y.Y., R, Fitzgerald, "Peer Learning with Concept Cartoons Enhance Critical Thinking (CRiTT) and Performance in Secondary School Economics," Journal of Economics and Economic Education, vol.18, Issue 1, pp.1-13,2017.

[6] Duizer C., Van den Heuvel-Panhuizen M., Veldhuis M., M Doorman, "Supporting primary school students' reasoning about motion graphs through physical experiences Springer," ZDM, 2019 51:899-913. DOI10.1007/s11858-019-01072-6

[7] Aydemir A.Z "Connotations in Architectural Design Education," In DAKAM- ARCDESIGN' $141^{\text {st }}$ Architectural Design Conference $8^{\text {th }}-10^{\text {th }}$ May 2014, Instabul pp. 91-99.

[8] Secken N., N Yoruk, "An analysis of relations between concerns about the use of graphs in chemistry classes and multiple intelligences in terms of different variables," International Journal of New Trends in Arts, Sports \& Science Education. Vol. 1, no. 2, pp. 142-156,2012

[9] Berg C. A., P Smith, “Assessing students' abilities to construct and interpret line graphs: disparities between multiple choice and free-response instruments," Science Education, Vol. 78, no. 6, pp. 527-554,1994 (https//doi.org/10.1002/sce.3730780602

[10] Glazer N. "Challenges with graph interpretation: a review of the literature," Studies in Science Education, vol. 47, no. 2, pp 183-210, 2011. DOI 10.1080/03057267.2011.605307

[11] Tairab H. H., A.K Khalaf Al-Naqbi, "How do secondary school science students interpret and construct scientific graphs?” Journal of Biological Education. vol. 38, no. 3, pp $127-132,2004$

[12] Lapp D, V.F. Cyrus, "Using Data Collection Devices To Enhance Students' understanding," Mathematics Teacher, vol. 93, no. 6, pp. 504-10 2000

[13] Roth W., M. S Temple, "On understanding variability in data: a study of graph interpretation in an advanced experimental biology laboratory," Educational Studies in Mathematics, vol. 86 no. 3, pp. 359-376,2014. DOI:10.1007/s10649-014-9535-5

[14] Angra A., M.S. Gardner, "Reflecting on Graphs: Attributes of Graph Choice and Construction Practices in Biology," CBE-Life Sciences Education, vol.16, no. 3,2017 DOI:10.1187/cbe.16-08-0245

[15] McDonnell, L.M. "Opportunity- to -Learn as a Research Concept and Policy Instrument," Educational Evaluation and Policy Analysis vol. 17, no. 3 pp. 305-322,1995

[16] Gau S. "The Distribution and the Effects of Opportunity to Learn on Mathematics Achievement," Annual Meeting of the American Educational Research Association, Chicago, IL, March 24-28,1997

[17] Boscardin C.K., Aguirre-Munoz Z., Stoker G., Kim J., Kim, M., J. Lee, "Relationship between Opportunity to Learn and Student Performance on English and Algebra Assessments," Educational Assessments, vol. 10 no. 4, pp. 307-322, 2005.DOI: 10.1207/s15326977ea1004_1 
[18] Scherff L., C.L. Piazza, "Why Now, More than Ever, We Need to Talk about Opportunity to Learn." Journal of Adolescent \& Adult Literacy 52/4:343-352,2005 Available: http//www.jstor.org/stable/4005813

[19] Husen T. "International Study of Achievement in Mathematics," Volume 2, 1967. New York: John Wiley

[20] Banicky L. A. “Opportunity to Learn education,” Education Policy Brief, vol. 7, October 2000

[21] Scheerens J. "Educational Effectiveness and Ineffectiveness," A critical review of the knowledge base. Dordrecht, Heidelberg, London, New York: Springer, 2016.

[22] Stols G. "An investigation into the opportunity to learn that is available to Grade 12 mathematics learners," South African Journal of Education, vol. 33, no. 1, 2013. http://sajournalofeducation.co.za

[23] Valverde G.A. "Educational Quality: Global Politics, Comparative Inquiry, and Opportunities to Learn," Comparative Education Review, vol. 58, no. 4, pp 375-589, 2014.DOI 10. 1086/678038

[24] Walkowiak T.A, Pinter, H. H., R.Q. Berry, “A conceptualised Framework for Opportunity to Learn in School Mathematics," Journal of Mathematics Education at Teacher's College, Vol 8, no. 1 pp 2-18,2017

[25] Sirotic N, A. Zazkis, "Irrational Numbers: The Gap between Formal and Intuitive Knowledge," Educ Stud Math 65, 49-76. DOI :10.1007/s10649-006-9041-5

[26] Suleman Q., Aslam, D.H., I.Husain, Effects of Parental Socioeconomic Status on the Academic Achievement of Secondary School Students in District Karak (Pakistan) Zaib-un," International Journal of Human Resource Studies Vol. 2, no. pp 44-19 2013. DO:10.5296/ijhrs.v.2i4.2511

[27] Handayani S, "Impact of Blended Learning on Student Learning Result in Microeconomics Course," Classroom Action Research Journal, vol. 1, no. 4, pp 192-199,2018. DOI:10.17977/um013v2i32018p133.

[28] Gillies J., J.J. Quijada, “Opportunity to learn: a high impact strategy for improving educational outcomes in developing countries," Academy for Educational Development, Washington D.C.,2008

[29] Chabongora B. N., L.C. Jita, “Opportunities to Learn (OTL) Grade 10 Algebra in Three South African Catholic Secondary Schools," Journal of Educational Studies, vol.12, no.1, pp 172-188.2013

[30] Reche R. N., Bundi T. K., Riungu J. N., Z.K. Mbungua, "Factors Contributing to Poor Performance in Kenya Certificate of Primary Education in Public Day Primary Schools in Namibia Division," International Journal of Humanities and Social sciences, vol. 2, no. 5, pp $127-133,2012$

[31] Stanley M., S. Nayar, "Qualitative research methodologies for occupational science and therapy, Routledge: New York, 2015

[32] Creswell J. W., J.D. Creswell "Research design: Qualitative, quantitative, and mixed methods approaches" Sage publications, 2017

[33] Baxter P., S. Jack, “Qualitative case study methodology:
Study design and implementation for novice researchers," Qualitative report vol. 13, no. 4 pp544-559,2008 https://nsuworks.nova.edu/tqr/vol13/iss4/2

[34] Rahi S. "Research Design and Methods: A systematic Review of Research Paradigms, Sampling Issues and Instruments Development," International Journal of Economics and Management Sciences, Scie 6:403,2017, DOI 10.4172/2162-6359.1000403

[35] Woiceshyn J., U. Daellenbach "Evaluating inductive vs deductive research in Management studies:Implications for authors,editors, and reviewers, Qualitative Research in Organisations and Management," An International Journal, vol. 13, no. 2, pp 183-195, 2018. DOI. 10.1108/QROM-06-2017-1538

[36] Bansal P., Smith W. K., E Vaara, "New Ways of Seeing through Qualitative Research," Academy of Management Journal, pp 1189-1195, 2018. https://hal.archives-ouvertes.f r/hal-02276705

[37] Silverman D. "Qualitative research," London: Sage Publications, 2016

[38] Saputri S., Larasati F., M Febriyani Än Analysis of Parents' Perceptions on the Importance of Homework in Improving English Achievement," English Community Journal, vol. 4, no 2, pp109-121, 2020.http://jurnal.um-palembang.ac.id/en glishcommunity/index

[39] Buitrago-Florez F., Reyes J. C., Rincon R., Hernandez C., Gavis F., C Angel "Engaging in homework development: TARSIS platform as an innovative learning methodology," Australasian Journal of Education Technology, vol. 36, no. 3, pp 147-162, 2020.https://doi.org/10. 14742/ajet.5865

[40] Morrison J., A. "McDuffie Connecting Science and Mathematics: Using Inquiry Investigations to Learn About Data Collection, Analysis, and Display," School Science and Mathematics, vol. 109, no.1, DO:10.1111/j.1949-8594. 2009.tb17860.x

[41] Kriz W., W. Manahl, "Understanding and changing systems through hybrid simulation game design methods in educational context," Simulation and Gaming Society Vol 9, 79-93, 2016

[42] Bonner J. "Taking a Stand as a Student- Centred Research University: Active and Collaborative Learning Meets Scholarship of Teaching at University of Alabam,"'The Journal of General Education, Vol. 59, No. 4, pp 183-192,2010 DOI:10.5325/jgeneedue.59.4.0183

[43] Benlahcene A., Lashari A. S., Lashari A.T., Shehzad W. M., W Deli "Exploring the Perception of Students using Student- Centered Learning Approach in a Malaysian Public University," International Journal of Higher Education, vol. 9, No. 1, 2020 http://ijhe.sciedupress.com

[44] Van Wyk M. M. "The use of cartoons as a teaching tool to enhance student learning in economics education," Journal of Social Science, vol. 26, no. 2 pp, 117-130, 2011. DOI:10.1080/09718923.2011.11892888

[45] Harsh J. A., M Smit-Harsh, "Instructional Strategies to Develop Graphing Skills in the College Science Classroom," The American Biology Teacher, vol. 78, no. 1, pp 49-56, 2016. DOI:10.1525/abt.2016.78.1.49

[46] Nilson L. B. "Teaching at its Best: A research- based 
resource for college," $3^{\text {rd }}$ edition. San Francisco: Jossey-Bass, 2010

[47] Chung-Kai Huang, Chun-Yu Lin, Zih-Cin Lin, Cui Wang., Lin, Chia-Jung "Optimize Knowledge Sharing, Team Effectiveness, and Individual Learning within the Flipped Team-Based Classroom," National Taipei University of
Business, Taiwan: International Conference Educational Technologies, 2017

[48] Ruey S. "A case study of constructivist instructional strategies for adult online learning," British Journal of Educational Technology, vol. 4, no. 5, pp 706-720, 2010. DOI:10.1111/j.1467-8535.2009.00965.x 